DOI: 10.12957/demetra.2017.25475

\title{
Dark polyphenols-rich chocolate and gut microbiota: a literature review
}

\section{Polifenóis do chocolate amargo e microbiota intestinal: uma revisão da literatura}

\author{
Vivianne Pereira Simões de Oliveira' \\ Manuela Dolinsky² \\ Sérgio Girão Barroso² \\ Milena Barcza Stockler Pinto ${ }^{1}$ \\ Sofia Kimi Uehara ${ }^{3}$ \\ Gabrielle de Souza Rocha ${ }^{2}$ \\ 1 Universidade Federal Fluminense, Programa \\ de Pós-graduação em Ciências Cardiovasculares. \\ Niterói-RJ, Brasil. \\ ${ }^{2}$ Universidade Federal Fluminense, Curso de \\ Nutrição. Niterói-RJ, Brasil. \\ ${ }^{3}$ Universidade Federal do Rio de Janeiro, \\ Programa de Pós-graduação em Cardiologia. \\ Rio de Janeiro-RJ, Brasil. \\ Correspondence / Correspondência \\ Vivianne Pereira Simões de Oliveira \\ E-mail:vivianne.siimoes@gmail.com
}

\begin{abstract}
Dark chocolate has been widely used in research due to its beneficial effects in a variety of organ systems and antioxidant capacity in function of polyphenol content derived from cocoa (Theobroma cacao). There is strong evidence that life stress impacts directly on gastrointestinal function in animals and humans via modulation of key physiological parameters, such as intestinal permeability and secretion and release of biological mediators. Changes of gastrointestinal functional ecology are intimately linked to microbial populations and activities, and abnormal microbiota composition is often observed in the development of irritable bowel syndromes. Studies show that dark chocolate plays a role in various human diseases, which can be by modulation of intestinal microbial species as demonstrated in recent studies published. This study aimed to evaluate research on dark chocolate intake effects on intestinal microbiota through scientific literature, focusing on reciprocal interactions between the intestinal microbiota and polyphenols, mechanisms of action and the consequences of these interactions on human health.
\end{abstract}

Keywords: Chocolate. Cacao. Microbiota. Gastrointestinal Microbiome.

\section{Resumo}

O chocolate amargo tem sido amplamente utilizado em pesquisas devido a seus efeitos benéficos numa variedade de sistemas de órgãos e capacidade antioxidante em função do teor de polifenóis derivados do cacau (Theobroma cacao). Há fortes 
evidências de que o impacto do estresse atue diretamente sobre a função gastrointestinal em animais e humanos através da modulação dos principais parâmetros fisiológicos, tais como a permeabilidade intestinal e secreção e liberação de mediadores biológicos. Alterações da ecologia funcional gastrointestinal estão intimamente ligadas às populações e atividades microbianas, e a composição da microbiota anormal é frequentemente observada no desenvolvimento da síndrome do intestino irritável. Estudos mostram que o chocolate escuro desempenha um papel em várias doenças e distúrbios humanos, que pode ser por modulação das espécies microbianas intestinais, como demonstrado em estudos recentes publicados. O objetivo deste estudo foi investigar os efeitos da ingestão de chocolate amargo sobre a microbiota intestinal por meio da literatura científica, com foco em interações recíprocas entre a microbiota intestinal e polifenóis, mecanismos de ação e as consequências dessas interações sobre a saúde humana.

Palavras-chave: Chocolate. Cacau. Microbiota. Microbioma Gastrointestinal.

\section{Introduction}

Chocolate is a food industry product formed by ingredients combination as cocoa liquor, cocoa butter, sugar, milk and emulsifier, and can be classified in "milk", "semisweet" and "bitter or dark" according to ingredients proportion. In the dark chocolate (DC) classification, fat solids of cocoa beans in its processing is not considered, featuring the bitter and astringent taste. The bittersweet chocolate contains little sugar and may or may not have added milk. Due to its high cocoa concentration, dark chocolate has been highlighted as a food source of polyphenols. ${ }^{1}$

DC has been studied due to its beneficial effects in several organ systems. Its moderate consumption has been associated with improved lipid profile, insulin resistance, endothelial function, body composition and cognitive performance, as well as cancer prevention. ${ }^{2,3}$ This capacity is due to the high content of polyphenols in cocoa beans (Theobroma cacao), the main ingredient of DC. ${ }^{1}$

Polyphenols constitute a group of compounds with biological properties that can be naturally found in plants. However, their concentration in food can be impaired in processing and, in the case of chocolate, can be influenced by cocoa beans source and processing, as well as conservation methods. In this case, total content can be reduced up to $90 \%$ when compared with the polyphenol content in seeds. In addition, most polyphenols are not absorbed in the gut (90\%) and follow 
through colon, where are metabolized by intestinal bacteria, producing short chain fatty acids (SCFA) that are able to modulate intestinal microbiota composition. ${ }^{4}$

Several studies have showed the effects of dark chocolate in the gut microbiota, leading to positive changes in its composition and, hence, resulting in an increase in beneficial bacteria population such as Lactobacillus and Bifidobacterium genus. These effects on gut microbiota modulation are reciprocal. During digestion and absorption, intestinal microbiota is responsible for polyphenols hydrolysis and absorption, also influencing bacterial composition. ${ }^{5}$

This study aimed to gather findings of the literature on dark chocolate ability to modulate gut microbiota.

\section{Methods}

This is a narrative bibliographic review based on full scientific articles published on the internet about the dark chocolate impact on intestinal microbiota. The main question of the study was: "Can dark chocolate consumption positively modulate the gut microbiota?" The search was carried out through bibliographic databases, PubMed and "Periodicos CAPES" portal, from May 1, 2016 to August 1, 2016, using the following descriptors: dark chocolate, cocoa, microbiota and gastrointestinal microbiome. Articles published in Portuguese and English have been selected from the last 10 years. After each database search, duplicate references were deleted. Studies carried out in humans, animals and "in vitro" were considered for the article elaboration.

\section{Human microbiota: overview of microbial colonization}

The range of bacteria present in intestinal microbiota is responsible for the nondigestible compounds fermentation, as fibers, synthesis of vitamin K, protection against food pathogen, epithelial maturation, generation of compounds with antioxidant activity, lipids with biologic activity (Lipopolysaccharides - LPS), short-chain fatty acids, gases (H2, CO2, CH4 and H2S), and stool formation. ${ }^{6}$

However, to develop these functions accurately, it is important to keep a balance between bacterial population, to avoid dysbiosis. Among important risks factors that alter microbiota composition, dietary habits have a major effect. Diets rich in vegetable-derived polysaccharides, for example, have been associated with high prevalence of genus Provotella. On the other hand, in subjects with high meat consumption , genus Bacteroides prevail. ${ }^{7}$

It is well established in the literature that dietary pattern influences colonic bacteria population profile, which are identified as low gene count (LGC) or high gene count (HGC). Individuals with 
low gene count present Bacteroides genus as dominant, which is usually associated with obesity and metabolic disturbances. However, when treated with focus on weight loss, these individuals tend to have a greater genetic diversity with improvement in symptoms of metabolic syndrome. ${ }^{6}$

Besides dietary habits, comorbid conditions can lead to a bacteria population imbalance, requiring the adoption of special care, as increased fiber consumption, use of probiotics or symbiotics, as well as using SCFA. The latter serve as source of energy for intestinal cells, and promote cell integrity maintenance. Therefore, the balance among bacterial groups on gut microbiota promotes SCFA production necessary to keep intestinal health. It occurs through presence of main bacteria phylum involved in SCFA synthesis. Phylum Bacteroidetes and phylum Firmicutis constitute the main bacteria group, producing propionate and butyrate, respectively. Among the bacteria found in smaller proportions, but with high intestinal health impact, one can mention Bifidobacterium, Lactobaccilus and Escherichia coli, belonging to Actinobacteria, Firmicutes and Proteobacteria phylum, respectively. ${ }^{6}$

Bifidobacterium and Lactobaccilus genus bacteria are able to suppress proinflammatory cytokine IL-6 and IL-17 expression, and to promote major tight junction expression, reducing visceral hypersensitivity. ${ }^{8}$ Thus, they are effective in reducing inflammatory bowel disease symptoms and improving individuals' well-being. ${ }^{9}$ Recent studies showed probiotics, including Bifidobacterium longum and Lactobacillus acidophilus, with hypocholesterolemic effects in both rat and human. Mechanisms involved may be the following: (1) fermentation products of lactic acid bacteria inhibit cholesterol synthesis enzymes and reduce cholesterol production; (2) bacteria facilitate cholesterol elimination in feces; (3) and inhibit cholesterol absorption back into the body by binding with cholesterol; (4) and interfere with bile salt recycling (a metabolic product of cholesterol) and facilitate its elimination, raising bile salt demand made from cholesterol and resulting in body cholesterol consumption; and (5) lactic acid assimilation. ${ }^{6,9,10}$

Moreover, bifidobacteria acetate production could enhance intestinal epithelial cells mediated defense, protecting the host against $E$. coli $\mathrm{O} 157: \mathrm{H} 7$ infection. ${ }^{11} \mathrm{E}$. coli strains are found in relatively lower numbers than other major commensal bacteria. However, it is the most common cause of intestinal and extra-intestinal disease. Pathogenic $E$. coli strains may carry several virulence factors directly involved in these bacteria pathogenesis, although commensal strains might also cause disease in immunocompromised hosts. ${ }^{12}$

Colonization is not restricted to gut, however. Some studies point out to Streptococcus colonization throughout the digestive tract, in esophagus distal portion and stomach. Esophagus microbial diversity, as genera Prevotella, Actinomyces, Lactobacillus, and Staphylococcus, is related to chronic inflammation and dysplasia. Bacterial population limitation is also present in the stomach due to low gastric $\mathrm{pH}$ acid. The $\mathrm{pH}$ favors $\mathrm{H}$. pylori colonization, which can remain many years without symptoms, but it can lead to gastric cancer cases, gastritis and peptic ulcers. Nevertheless, the 
stomach most commonly found bacteria are Prevotella, Streptococcus, Veillonella and Rothia. Intestinal colonization is also able to promote behavioral changes through the gut-brain axis. Intestinal dysbiosis condition with increased Ruminococcus gnavus and Ruminococcus torques genera is associated with autism in children. ${ }^{13}$ So microbiota modulation would be able to increase or decrease the exploratory behavior of this group.

Another study with mice inoculated with Salmonella submitted to stress condition by food deprivation presented Lactobacillus genus reduction. In addition, stress itself led to Verrucobacteria and Clostridium spp imbalance. However, this situation could be reversed through the introduction of a probiotics diet. ${ }^{14}$

\section{Dark chocolate as functional food}

Functional foods are classified as food or food ingredient consumed as part of the normal diet that contains bioactive compounds able to produce beneficial health effects. ${ }^{15}$ In this scenario, a market for functional foods has been developed, and nowadays plays an important role in food industry, due to the increasing demand for healthier products with beneficial properties to the body. Recently, compounds in chocolate have been found to bring health benefits, and chocolate has been included in the group of functional foods. In addition, chocolate is frequently associated with pleasure and stress reduction, as well as other properties discussed throughout this review..$^{16,17}$

Cocoa polyphenols represent about 5-6\% of its dry weight, and are subdivided in 6 groups: flavanols, flavonols, anthocyanins, flavones, flavanones e isoflavones. Cocoa contains flavanols in monomer (epicatechin and catechin), oligomer, and polymer (proanthocyanidins) forms, as well as anthocyanins, flavonol glycosides, clovamide, dideoxyclovamide, phenylethylamine, N-oleoyl- and N-linoleoylethanolamine, and theobromin. However, catechin, epicatechin and their oligomers are the main active compounds from the flavonoids group, being (-) - epicatechin the most abundant, representing $35 \%$ of total phenolic compounds content. ${ }^{17}$ The latter can be absorbed completely in gut, with peak about 2 hours after ingestion and may be detectable in blood for up to 8 h. ${ }^{18,19}$

Instead of white chocolate, which has cocoa butter in its composition (containing at least 20\% [g / $100 \mathrm{~g}$ ] of total solids of cocoa butter), research has shown dark chocolate promoting systolic and diastolic blood pressure reduction, flow-mediated dilation increase, improved insulin sensitivity and cognitive performance, innate and adaptive immune system stimulation, as well as reduced cerebral oxidative stress. ${ }^{20}$

Concerning cardioprotective effects, a meta-analysis using randomized controlled trials associated dark chocolate or cocoa drinks intake with a significant reduction in total and LDL cholesterol in participants after intervention. ${ }^{21}$ Another study performed with Swedish women, using regular chocolate consumption (1-2 per serving / week), reduced chances of developing 
heart failure by 32\%. These results can be explained by Fraga et al., who related cocoa and its derivatives, such as chocolate, with blood pressure reduction capacity in animals and humans through nitric oxide $(\mathrm{NO})$ production. ${ }^{22}$

Regarding antioxidant capacity, one study found cocoa powder with significantly higher antioxidant capacity compared to acai, blueberry powder, cranberry or pomegranate powder. Furthermore, flavonols content was significantly higher in cocoa powder, compared with other kinds of fruit. ${ }^{23}$ These findings justified the use of DC as functional foods in clinical practice.

\section{Dark chocolate consumption and microbiota modulation}

In vitro studies

Besides stimulating beneficial bacteria growth, in vitro studies have found that cocoa powder is related to pathogenic species foodborne inhibition, as Escherichia coli O157: H7 (EHEC), Salmonella typhimurium, and Listeria monocytogenes; it also reduces these pathogens invasiveness to host cells. ${ }^{24}$

Phenolic compounds fermentation of DC 90\% cocoa, as epicatechin, catechin, and procyanidin B-type polymers resulted in metabolites production of 5- (3 ' 4' -dihydroxyphenyl) - $\gamma$ - valerolactone, (3,4-dihydroxyphenyl) acetic acid and protocatechuic acid. These are already detectable in the blood up to 24 hours after colonic fermentation, making these metabolites potential flavan-3-ol consumption markers in humans. ${ }^{25-27}$ Moreover, the literature associates catechin fermentation with an increase in Clostridium coccoides, Eubacteriumrectale, Bifidobacterium spp. and Escherichia coli bacteria group, and inhibition of bacteria C. histolyticum. ${ }^{26}$

Colonic bacteria metabolic SCFA production activity appears to be stimulated by DC fermentation, with polydextrose addition. Most SCFA ( $\geq 95 \%)$ are represented by ethyl (C2), propionate (C3) and butyrate (C4), and are rapidly absorbed by colonocytes, acting as cell energy source, in addition to beneficial effects such as intestinal barrier improvement function, stimulating cancer cells apoptosis and anti-inflammatory effects..$^{28}$

\section{Animal studies}

A study with female Wistar rats on AIN-93M diet pattern foods with standard diet with $10 \%$ cocoa (10.62 mg / g polyphenols) for six weeks was conducted. Even when there was no significant difference in total bacterial counts in groups with or without supplementation, the group fed diet with 10\% cocoa showed a reduction in the proportion of Bacteroides, Staphylococcus and Clostridium genus bacteria $(\mathrm{p}<0,05) \cdot{ }^{29}$ 
In relation to microbiota modification and generation of specific metabolites, phenolic compounds can alter immune response through lymphoid tissues functionality engagement in rats, such as gut associated lymphoid tissue (GALT), resulting in a loss in IgA secretion. This reduction appears to be associated with reduced bacteria proportion of Clostridium and Streptococcus genus. Diet rich in cocoa polyphenols is also capable of inducing toll-like receptors expression (TLR) change in small intestine, reducing TLR9 receptor and tendency of decreased TLR2 and TLR7 expression. TLRs are responsible for microbial pathogens recognition through molecular patterns structures associated with the pathogen (PAMPs). Thus, differentiation in these expressions generate TLR subclasses, allowing changes in intestinal microbiota composition. ${ }^{29}$

Also regarding the immunological effect, a randomized study of pigs submitted to different cocoa powder concentrations ( $0 \mathrm{~g}, 2.5 \mathrm{~g}, 10 \mathrm{~g}, 20 \mathrm{~g})$ for 27 days, observed a TLR9 reduction in ileum Peyer's patches and mesenteric lymph of pigs fed 2.5-20 g cocoa powder / d , compared with pigs not supplemented. Concerning microbiota modulation, significant increase of Lactobacillus genus was observed ( 7 fold, $\mathrm{P}=0.005$ ) in feces when compared to unsupplemented pigs. Nevertheless, there was a increased Bidifubacterium genus ( 9 fold, $\mathrm{P}=0.01$ ) in the contents of the proximal colon. ${ }^{30}$

In addition to changes related to microbiota modulation, a study performed with male C5BL / 6 mice randomized into high fat (HF) diet, HF diet with $8 \%$ cocoa powder and low fat (LF) diet groups followed for 18 weeks, observed a metabolic endotoxemia improvement, as well as intestinal function, by increased glucagon-like peptide 2 (GLP-2) plasma levels in HF diet group (8\% cacao powder), when compared with HF and HF /LF diet groups, respectively. ${ }^{31}$

Another study, male Sprague Dawley rats was randomized in 3 groups : standard diet, standard diet supplemented with $10 \%$ of dark chocolate and standard diet supplemented with $10 \%$ of dark chocolate presenting "fat bloom" (whitish layer formed on the surface due to lipid oxidation) for 6 weeks. It was observed that regular consumption of dark chocolate and chocolate featuring "fat bloom" reduced colonic crypts proliferation significantly, suggesting benefits of dark chocolate in colorectal cancer treatment. ${ }^{32}$

\section{Human studies}

Martin et al. showed that $40 \mathrm{~g}$ of chocolate consumption ( $74 \%$ cocoa) during two weeks in subjects treated for anxiety was able to reduce urinary excretion of phenyl-acetyl-glutamine and p-cresol sulfate, suggesting an adaptation of the microbiota intestinal to dark chocolate active compounds. Urinary excretion of trimethylamine (TMA) and hippurate increase was also observed. These data suggest phenolic compounds presence, indoles and derivatives, benzoic, methylamines, short chain fatty acid and its metabolites, providing indirect microbial composition, allowing changes in microbial activity identification. ${ }^{33,34}$ 
Concerning bacterial composition changes, dark chocolate consumption was reported in the literature predominantly by Bifidobacterium and Lactobacillus growing populations, and inhibition of Clostridium group. ${ }^{34,35}$ Clostridium group, however, appears to be involved in the synthesis of p-cresol sulfate, a potentially toxic compound produced in the colon from the tyrosine and tryptophan. ${ }^{36}$

A double-blind study with chocolate intake modified containing sugar substitutes (maltitol, maltitol and polydextrose, and maltitol associated with resistant starch) for 14 days, showing significant increase in Lactobacillus and Bifidubacteria population in all chocolate tests. However, increase in Lactobacillus and greater production of propionate and butyrate were more pronounced in the polydextrose group. Bacteridoides population was significantly higher in groups receiving modified chocolate. These data suggest that replacement of sugar in chocolate, while reducing total calories, may also modulate microbiota positively, improving gut health biomarkers. ${ }^{37}$

\section{Conclusion}

Despite the lack of studies using dark chocolate, data suggest that its consumption may be encouraged in moderation and combined with a diet rich in fiber, in order to maintain healthy gut microbiota.

Concerning its use as prebiotic, the chocolate market seems to be promising due to increased demand for healthier options, coupled with its ability to maintain integrity of microorganisms and palatability.

This review shows that consumption of dark chocolate or cocoa flavanols can significantly affect selected gut microbiota growth, suggesting potential prebiotic benefits associated with dietary inclusion of flavanol-rich foods.

\section{Contributors}

All authors contributed worked in all steps, which consisted in study design; collection, analysis and interpretation of data, manuscript writing and proof-reading of final copy.

Conflict of Interest: The authors declare no conflict of interest. 


\section{References}

1. Katz DL, Doughty K, Ali A. Cocoa and Chocolate in Human Health and Disease. Antioxidants \& Redox Signaling 2011 Nov 15;15(10):2779-811.

2. Djoussé L, Hopkins PN, North KE, Pankow JS, Arnett DK, Ellison RC. Chocolate Consumption is Inversely Associated with Prevalent Coronary Heart Disease: The National Heart, Lung, and Blood Institute Family Heart Study. Clinical nutrition (Edinburgh, Scotland) 2011 Apr;30(2):182-7.

3. Gu Y, Yu S, Lambert JD. Dietary cocoa ameliorates obesity-related inflammation in high fat-fed mice. European journal of nutrition 2014 Feb;53(1):149-58.

4. Wang TY, Liu M, Portincasa P, Wang DQ-H. New insights into the molecular mechanism of intestinal fatty acid absorption. European Journal of Clinical Investigation 2013 Sep;n/a-n/a.

5. Hayek N. Chocolate, gut microbiota, and human health. Frontiers in Pharmacology [Internet]. 2013 [cited 2016 Jul 11];4(11). Available from: http://journal.frontiersin.org/article/10.3389/ fphar.2013.00011/abstract

6. Graf D, Di Cagno R, Fåk F, Flint HJ, Nyman M, Saarela M, et al. Contribution of diet to the composition of the human gut microbiota. Microbial Ecology in Health and Disease 2015 Feb4;26:261-4.

7. Etxeberria U, Fernández-Quintela A, Milagro FI, Aguirre L, Martínez JA, Portillo MP. Impact of polyphenols and polyphenol-rich dietary sources on gut microbiota composition. Journal of agricultural and food chemistry 2013 Oct 9;61(40):9517-33.

8. Wang H, Gong J, Wang W, Long Y, Fu X, Fu Y, et al. Are There Any Different Effects of Bifidobacterium, Lactobacillus and Streptococcus on Intestinal Sensation, Barrier Function and Intestinal Immunity in PI-IBS Mouse Model? PLoS ONE. 2014, March 3;9(3):p.e90153.

9. Tojo R, Suárez A, Clemente MG, de los Reyes-Gavilán CG, Margolles A, Gueimonde M, et al. Intestinal Microbiota in Health and Disease: Role of Bifidobacteria in Gut Homeostasis. World journal of gastroenterology. 2014 Nov 7;20(41):15163-76.

10. Collado MC, Isolauri E, Laitinen K, Salminen S. Effect of mother's weight on infant's microbiota acquisition, composition, and activity during early infancy: a prospective follow-up study initiated in early pregnancy. The American Journal of Clinical Nutrition 2010 Nov; 92(5):1023-30.

11. Fukuda S, Toh H, Hase K, Oshima K, Nakanishi Y, Yoshimura K, et al. Bifidobacteria can protect from enteropathogenic infection through production of acetate. Nature 2011; 469:543-547.

12. Katouli M. Population Structure of Gut Escherichia Coli and Its Role in Development of ExtraIntestinal Infections. Iranian Journal of Microbiology 2010 Jun;2(2):59-72.

13. Wang L, Christophersen CT, Sorich MJ, Gerber JP, Angley MT, Conlon MA. Increased abundance of Sutterella spp. and Ruminococcus torques in feces of children with autism spectrum disorder. Molecular Autism 2013 Nov 4;4:42. 
14. Tannock G, Savage D. Influences of Dietary and Environmental Stress on Microbial Populations in the Murine Gastrointestinal Tract. InfectionandImmunity 1974 Mar; 9(3): 591-598.

15. Ministério da Saúde. Dicas em saúde. Alimentos funcionais. Disponível em: http://bvsms.saude.gov. br/bvs/dicas/220_alimentos_funcionais.html

16. Konar N, Toker OS, Oba S, Sagdic O. Improving functionality of chocolate: A review on probiotic, prebiotic, and/or synbiotic characteristics. Trends in Food Science \& Technology 2016 Mar;49:35-44.

17. Koli R, Köhler K, Tonteri E, Peltonen J, Tikkanen H, Fogelholm M. Dark chocolate and reduced snack consumption in mildly hypertensive adults: an intervention study. Nutr J [Internet]. 2015 Aug 22 [cited 2016 Apr 27];14. Available from: http://www.ncbi.nlm.nih.gov/pmc/articles/PMC4546094/

18. Andújar I, Recio MC, Giner RM, Ríos JL. Cocoa polyphenols and their potential benefits for human health. Oxidative Medicine and Cellular Longevity 2012;2012:906252.

19. Efraim P, AlvesAB, Jardim DCP. Review: Polyphenols in cocoa and derivatives: factors of variation and health effects. Brazilian Journal of Food Technology 2011 Sep;14(3):181-201.

20. Nehlig A. The neuroprotective effects of cocoa flavanol and its influence on cognitive performance. British Journal of Clinical Pharmacology 2013 Mar;75(3):716-27.

21. Tokede O, Gaziano J, Djoussé L. Effects of cocoa products/dark chocolate on serum lipids: a metaanalysis. European Journal of Clinical Nutrition. 2011;65:879-86.

22. Fraga CG, Litterio MC, Prince PD, Calabró V, Piotrkowski B, Galleano M. Cocoa flavanols: effects on vascular nitric oxide and blood pressure. Journal of Clinical Biochemistry and Nutrition 2011 Jan;48(1):63-7.

23. Crozier SJ, Preston AG, Hurst JW, Payne MJ, Mann J, Hainly L, et al. Cacao seeds are a "Super Fruit": A comparative analysis of various fruit powders and products. Chemistry Central Journal 2011;5:5.

24. Peng M, Aryal U, Cooper B, Biswas D. Metabolites produced during the growth of probiotics in cocoa supplementation and the limited role of cocoa in host-enteric bacterial pathogen interactions. Food Control 2015 Jul;53:124-33.

25. Dall'Asta M, Calani L, Tedeschi M, Jechiu L, Brighenti F, Del Rio D. Identification of microbial metabolites derived from in vitro fecal fermentation of different polyphenolic food sources. Nutrition 2012 Feb;28(2):197-203.

26. Tzounis X, Vulevic J, Kuhnle GGC, George T. Flavanol monomer-induced changes to the human faecalmicroflora. The British Journal of Nutrition 2008;99(4):782-92.

27. Goodrich KM, Dorenkott MR, Ye L, O’Keefe SF, Hulver MW, Neilson AP. Dietary Supplementation with Cocoa Flavanols Does Not Alter Colon Tissue Profiles of Native Flavanols and Their Microbial Metabolites Established during Habitual Dietary Exposure in C57BL/6J Mice. Journal of Agricultural and Food Chemistry 2014 Nov 19;62(46):11190-9.

28. Verbeke KA, Boobis AR, Chiodini A, Edwards CA, Franck A, Kleerebezem M, et al. Towards microbial fermentation metabolites as markers for health benefits of prebiotics. Nutrition Research Reviews 2015 Jun;28(1):42-66. 
29. Massot-Cladera M, Pérez-Berezo T, Franch A, Castell M, Pérez-Cano FJ. Cocoa modulatory effect on rat faecalmicrobiota and colonic crosstalk. Archives of Biochemistry and Biophysics 2012 Nov;527(2):105-12.

30. Jang S, Sun J, Chen P, Lakshman S, Molokin A, Harnly JM, et al. Flavanol-Enriched Cocoa Powder Alters the Intestinal Microbiota, Tissue and Fluid Metabolite Profiles, and Intestinal Gene Expression in Pigs. The Journal of nutrition 2016 Apr;146(4):673-80.

31. Gu Y, Yu S, Park JY, Harvatine K, Lambert JD. Dietary cocoa reduces metabolic endotoxemia and adipose tissue inflammation in high-fat fed mice. The Journal of Nutritional Biochemistry 2014 Apr;25(4):439-45.

32. Hong MY, Nulton E, Shelechi M, Hernández LM, Nemoseck T. Effects of Dark Chocolate on Azoxymethane-Induced Colonic Aberrant Crypt Foci. Nutrition and Cancer 2013 Jul;65(5):677-85.

33. Martin F-PJ, Rezz S, Peré-Trepat E, Kamlage B, Collino S. Metabolic effects of dark chocolate consumption on energy, gut microbiota, and stress-related metabolism in free-living subjects. Journal of proteome research 2009;8(12):5568-79.

34. Martin F-PJ, Montoliu I, Nagy K, Moco S. Specific dietary preferences are linked to differing gut microbia. Journal of proteome research 2012;11(12):6252-63.

35. Tzounis X, Rodriguez-Mateos A, Vulevic J, Gibson GR, Kwik-Uribe C, Spencer JPE. Prebiotic evaluation of cocoa-derived flavanols in healthy humans by using a randomized, controlled, doubleblind, crossover intervention study. The American Journal of Clinical Nutrition 2011 Jan;93(1):62-72.

36. Patel KP, Luo FJ-G, Plummer NS, Hostetter TH, Meyer TW. The Production of p-Cresol Sulfate and Indoxyl Sulfate in Vegetarians Versus Omnivores. Clinical Journal of the American Society of Nephrology 2012 Jun 1;7(6):982-8.

37. Beards E, Tuohy K, Gibson G. A human volunteer study to assess the impact of confectionery sweeteners on the gut microbiota composition. The British journalofnutrition 2010 Sep;104(5):701-8.

Received: September 09, 2016

Reviewed: March 31, 2017

Accepted: May 15, 2017 
